\title{
UM LIVRO-HOMENAGEM: \\ a mais recente biografia de Michel Foucault
}

\section{Viviane Trindade Borges ${ }^{*}$}

VEYNE, Paul. Foucault, sa pensée, sa personne. Paris: Albin Michel, 2008.

Conforme Paul Veyne, Foucault sugeriu, imprudentement, que em nossa época a humanidade começa a aprender que poderia viver sem mitos, sem religião e sem filosofia, sem verdades gerais sobre ela mesma. No entanto, a tessitura da análise empreendida pelo historiador acaba instituindo um mito, um herói, como ele mesmo se refere a Foucault em vários momentos. Lançado em 2008, seu livro Foucault: sa pensée, sa personne foi traduzido para o português de Portugal em $2009^{1}$. O trabalho pode ser pensado como um livrohomenagem, uma biografia que se traduz em testemunhos carregados de admiração. $\mathrm{O}$ autor, colega e amigo do biografado, escreveu uma obra permeada por depoimentos pessoais, na qual se misturam vida e obra do filósofo.

Na introdução, Veyne utiliza duas metáforas interessantes para caracterizar o herói de seu livro. Primeiro, compara Foucault a um peixe que consegue transcender o aquário em que vive. Essa figura inquieta extrapola sua própria realidade, observando os demais "peixinhos vermelhos" do lado de fora, sem, contudo, deixar de ser mais um habitante do aquário. Num segundo momento, o autor descreve seu personagem como uma "esgrima intelectual", que usava sua caneta com a mesma destreza que um samurai usa seu sabre afiado. Conforme Paul Veyne, Foucault escrevia seus livros "à espada", como se usasse o sabre de um samurai, e com certa ironia afirma que seu livro poderia se chamar "O samurai e o peixinho vermelho".

\footnotetext{
* Doutora em História pela Universidade Federal do Rio Grande do Sul. Professora Adjunta do Departamento de Historia da Universidade do Estado de Santa Catarina. E-mail: borgesviviane@hotmail.com

${ }^{1}$ VEYNE, Paul. Foucault o pensamento a pessoa. Lisboa: Pilares, 2009. A presente resenha refere-se à edição francesa.
} 
Ao longo de 200 páginas, divididas em 11 capítulos, o historiador perpassa diferentes conceitos foucaultianos e as discussões por eles suscitadas, numa análise rigorosa e pontual, ao longo da qual os pontos sensíveis e polêmicos da obra do filósofo são tocados com sutileza. As percepções de Foucault a respeito do discurso, do saber, da verdade, do poder, da formação do homem como sujeito, foram todas problematizadas de forma clara e magistral. As aproximações e distanciamentos do olhar de Foucault em relação às obras de Kant, Wittengenstein, Nietzche, entre outros, se entrelaçam pela escrita de Veyne, compondo o olhar foucaultiano em diferentes momentos de sua trajetória.

Das inúmeras inquietações elucidadas e provocadas pelo referido livro, chama a atenção tê-lo transformado em "herói”, num mito cuja obra ainda hoje desestabiliza e encanta diferentes campos do conhecimento. Contudo, ao mesmo tempo, desmistifica e humaniza suas posições e atitudes, brinca com seus depoimentos, mostrando seu senso de humor refinado, suas convicções apaixonadas, mas também suas misérias e suas fraquezas.

Conforme o historiador, Foucault foi um pensador cético. Esta afirmação teria sido legitimada pelo próprio filósofo 25 dias antes de sua morte, durante uma entrevista. Foucault teria resumido seu pensamento numa só palavra ao responder que “sim”, “absolutamente”, ele se considerava um cético. O personagem de Veyne era um observador que duvidava de qualquer certeza, jamais aceitando ideias gerais. Este olhar cético não se referia aos fatos históricos em si; ele não duvidava de sua existência, mas dos questionamentos que lhes fazia, renunciando a verdades gerais e definitivas.

Veyne problematiza os conceitos foucaultianos, tais como discurso e verdade, por exemplo, mostrando que estavam impregnados de seu ceticismo em relação o mundo. Para Foucault, nós, os contemporâneos, estamos envolvidos por discursos, presos em aquários falsamente transparentes. Somos apreendidos, classificados e tomados por verdades por nós criadas, pois cada época é dona de sua própria verdade. Vivemos em prisões transparentes, sem mesmo perceber que esta prisão existe. Sem dúvida, uma forma cética de olhar o mundo.

Veyne afirma que Foucault vê a humanidade prisioneira dos discursos de sua época. Somos condicionados por discursos. Estes são os óculos através dos quais, a cada época, os homens percebem as coisas, pensam e agem. Os discursos são, portanto, singularidades datadas, práticas que instituem figuras sociais, imprimindo determinado sentido às trajetórias e aos fatos históricos. Assim, sob o olhar cético de Foucault, não há nenhuma transcendência fundadora, pois os sujeitos são instituídos através de práticas discursivas.

Conforme Paul Veyne, Foucault não pretendeu criar uma teoria do sujeito; ao contrário, pretendia mostrar como o sujeito se constituía através de práticas de verdade e de 
práticas de poder. De acordo com a perspectiva do pensador, não podemos escapar das relações de poder, mas podemos modificá-las, pois somos sujeitos livres para resistir em maior ou menor escala. Mas mesmo diante desta liberdade, o sujeito livre não é soberano; longe disso, ele é modelado em cada época pelos discursos e dispositivos do período e reage, constituindo a si mesmo através de processos de subjetivação.

O ceticismo do personagem descrito por Veyne provocou polêmica entre alguns de seus leitores, que entenderam seu pensamento como algo um tanto agressivo, ou mesmo esquerdista. Foucault foi muitas vezes o centro das atenções, duramente criticado sob vários aspectos. Sua percepção de discurso, por exemplo, foi classificada como errônea, pois seu ceticismo desencorajava a humanidade, fazendo da história um processo anônimo, irresponsável e desesperante. Veyne aponta uma frase específica, a frase "fatal”, com a qual finaliza o livro “As palavras e as coisas” e a partir da qual Foucault passa a ser violentamente criticado: “l'homme s'effacera, comme à la limite de la mer un visage de sable”. De acordo com Veyne, é a partir desta provocação (pois para ele Foucault não era "nada além de um provocador”) que o filósofo adquire a reputação de "inimigo da espécie humana”. É esta frase “fatal” que passa a definir o estilo e a atitude de Foucault como escritor.

Veyne defende seu herói. Não se tratava, para ele, de um inimigo do sujeito humano; mostra, ao contrário, que o seu personagem acreditava que este sujeito somente não poderia fazer descer do céu uma verdade absoluta nem agir soberanamente no céu destas verdades, mas poderia agir contra as verdades e realidades de sua época ou inovar sobre elas. Assim, o pensamento foucaultiano é descrito como uma crítica à atualidade; nega-se a ditar prescrições para a ação, mas fornece conhecimento para que esta aconteça.

Segundo Veyne, Foucault não pretendia ser um intelectual especialista, daqueles que se indignam com certas singularidades ao longo de sua existência, ou no exercício de seu métier. Para o historiador, ele foi um novo tipo de intelectual, um intelectual específico que conhecemos por volta dos anos 1980. Este novo modelo de intelectual trabalhava muito e não vivia em estado de permanente indignação, nem de febre militante, mas atacava toda vez que encontrava abusos que considerasse intoleráveis, um verdadeiro herói agindo contra as injustiças.

De acordo com o historiador, Foucault nunca transformou suas ações militantes em doutrinas. Em momento algum utilizou seus pensamentos para dar a uma prática política um valor de verdade, nem em seus livros nem em suas aulas. No entanto, o engajamento do filósofo nos grandes debates de seu tempo contribuiu para questionar o papel do intelectual em nossa sociedade. Em sua atuação no Grupo de Informações sobre as Prisões - GIP -, por 
exemplo, Foucault não desejava ser porta-voz das reivindicações dos prisioneiros, mas chamar a atenção da sociedade para as condições desumanas em que estes viviam no encarceramento. Sua atuação, portanto, não deixava de ter um caráter político, visto que o grupo acabou estimulando um movimento de revolta em 35 prisões em 1971 e 1972.

Da mesma forma, a publicação de "Vigiar e Punir" (1975) não deixa de ser um dos resultados dessa experiência, problematizando a idéia de punição. Nesta perspectiva, podemos questionar se estas não seriam maneiras de usar seu pensamento e seus atos para legitimar sua militância. Veyne não interpreta a atuação de Foucault desta forma. Para o historiador, a tarefa de um intelectual, segundo Foucault, é arruinar as evidências, dissipar as familiaridades aceitas, e não tentar modelar a vontade política dos outros. Seu personagem não era nem esquerdista, nem freudiano, nem marxista, nem socialista, nem progressista, nem terceiromundista, nem heideggeriano; era apenas um inconformista, característica suficiente para classificá-lo em todas as posições citadas.

Veyne cria um herói. Um personagem que se destaca por seus livros e suas ideias, mas também por seus feitos, como na ocasião em que teria arriscado a própria vida para salvar as vítimas de um cabaré em chamas numa praia tunisiana. Para o autor, a vida e a obra de Foucault se entrelaçam, pois ele construía a si mesmo em suas obras. O historiador atenta para uma questão que para ele explica a intenção de seu personagem em seu métier: "porque um pintor trabalharia se não fosse para ser transformado por sua pintura?” Analisando a provocação feita por Foucault, Veyne não identifica nem o filósofo, nem o historiador, mas um artista, um pintor, que escrevia para não ter um rosto, para se desprender de si mesmo, para se transformar pelo seu próprio saber.

É ao final do livro que a narrativa de Veyne se torna mais pessoal, na medida em que temas delicados e perturbadores são perpassados, tais como a homossexualidade, as drogas e a Aids. A homossexualidade do filósofo é tecida inicialmente de forma descontraída. O historiador conta que Foucault lhe teria conferido o título de "homossexual de honra”, pois um homem aberto e instruído, tal como Veyne, não poderia "preferir as mulheres", e ressalta: “nossas brincadeiras mútuas sobre a diferença de nossos gostos amorosos eram rituais de nossa amizade”.

Para o autor, a homossexualidade e seus "sofrimentos" influenciaram o pensamento de seu herói e despertaram sensibilidades particulares que determinaram certos objetos de sua pesquisa e sua forma de pensar. Nesta perspectiva, a opção sexual de Foucault explicaria as razões pelas quais boa parte de sua energia intelectual foi dedicada a combater a 
normatividade imposta pelo saber relacionado ao sexo e a resistir aos efeitos deste poder que induz à formação de discursos de verdade.

Segundo Veyne, Foucault fazia uso de opium e LSD, mas ressalta que eram episódios controlados, que aconteciam em intervalos de meses, pois seu gosto por escrever e trabalhar predominava e impedia que tais vícios se tornassem hábitos frequentes. O historiador conta que, certa vez, ao finalizar um de seus cursos na Universidade de Berkeley (EUA), Foucault acordou de uma “viagem” produzida pelo LSD numa sauna gay, localizada num "ghetto" homossexual de San Francisco. Veyne parece lamentar, ressaltando que "foi disso que ele morreu”, pois foi possivelmente em lugares como este que ele teria contraído o vírus HIV, e afirma que dias antes de sua morte ainda era possível encontrar em seu escritório no Collège de France um panfleto publicitário da referida sauna.

No início dos anos 1980, a Aids ainda era um flagelo distante, percebida de forma pejorativa como o “câncer dos homossexuais”. De acordo com o autor, nenhum dos familiares de Foucault ficou sabendo da doença real que havia dado fim a sua existência. Até mesmo seus amigos (entre os quais ele próprio) só ficaram sabendo dias antes ou mesmo depois de sua morte. Em seus últimos dias, Foucault teria registrado a seguinte frase: "Eu sei que tenho Aids, mas, em minha histeria, eu esqueço”.

Em seu livro-homenagem, o historiador deixa clara a admiração por seu personagem, admitindo o desejo de que os jovens historiadores de hoje "sonhem em escrever" como Foucault. Para Veyne, o pensador cético acreditava em seus métodos e convidava os "leitores de boa vontade” a utilizá-los e a continuarem sua empreitada, como fazem muitos ainda hoje. O herói cético descrito por Paul Veyne não tinha medo da morte e certamente foi imortalizado por seu pensamento e por sua pessoa. Apesar de ter afirmado que nossa sociedade se havia dado conta que poderia viver sem mitos, Foucault continua sendo um deles.

Recebido em: Outubro/2010 Aprovado em: Dezembro/2010 